\title{
Non-monotonic repayment contracts are superior: an experimental approach
}

Citation for published version (APA):

Reiss, J. P., \& Wolff, I. (2007). Non-monotonic repayment contracts are superior: an experimental approach. METEOR, Maastricht University School of Business and Economics. METEOR Research Memorandum No. 053 https://doi.org/10.26481/umamet.2007053

Document status and date:

Published: 01/01/2007

DOI:

10.26481/umamet.2007053

Document Version:

Publisher's PDF, also known as Version of record

\section{Please check the document version of this publication:}

- A submitted manuscript is the version of the article upon submission and before peer-review. There can be important differences between the submitted version and the official published version of record.

People interested in the research are advised to contact the author for the final version of the publication, or visit the DOI to the publisher's website.

- The final author version and the galley proof are versions of the publication after peer review.

- The final published version features the final layout of the paper including the volume, issue and page numbers.

Link to publication

\footnotetext{
General rights rights.

- You may freely distribute the URL identifying the publication in the public portal. please follow below link for the End User Agreement:

www.umlib.nl/taverne-license

Take down policy

If you believe that this document breaches copyright please contact us at:

repository@maastrichtuniversity.nl

providing details and we will investigate your claim.
}

Copyright and moral rights for the publications made accessible in the public portal are retained by the authors and/or other copyright owners and it is a condition of accessing publications that users recognise and abide by the legal requirements associated with these

- Users may download and print one copy of any publication from the public portal for the purpose of private study or research.

- You may not further distribute the material or use it for any profit-making activity or commercial gain

If the publication is distributed under the terms of Article $25 \mathrm{fa}$ of the Dutch Copyright Act, indicated by the "Taverne" license above, 


\section{J. Philipp Reiss, Irenaeus Wolff}

Non-monotonic Repayment Contracts are

Superior: An Experimental Approach

$\mathrm{RM} / 07 / 053$

JEL code: C91, D82

\section{METE@R}

Maastricht research school of Economics of TEchnology and ORganizations

Universiteit Maastricht

Faculty of Economics and Business Administration P.O. Box 616

NL - 6200 MD Maastricht

phone : ++31433883830

fax : ++31433884873 


\title{
Non-monotonic Repayment Contracts are Superior: An Experimental Approach *
}

\author{
J. Philipp Reiss \\ Maastricht University \\ p.reiss@algec.unimaas.nl
}

\author{
Irenaeus Wolff \\ University of Erfurt \\ irenaeus.wolff@uni-erfurt.de
}

September 2007

\begin{abstract}
We experimentally investigate if theoretically superior non-monotonic repayment contracts yield superior results in the laboratory. We find replacing standard debt contracts with repayment-equivalent non-monotonic contracts increases entrepreneurial income by $170 \%$ and total surplus by $30 \%$.
\end{abstract}

\section{Introduction}

In a setting of external finance of entrepreneurial projects with limited liability, standard debt contracts induce inefficiently low effort, thus leading to substantial welfare losses. Non-monotonic contracts have been shown to overcome this problem under a wide range of parameter choices, see Innes (1990). If designed accordingly, they induce efficient effort choices. We experimentally study the non-monotonic contract and compare it to the standard debt contract. We find that the non-monotonic contract is as efficient as self-financed enterprise and significantly outperforms the standard debt contract.

Our setting of entrepreneurial external finance with moral hazard differs from typical principal-agent relationships since, here, it is not the outside investor who bears the burden of inefficient effort provision. Rather, it is the entrepreneur herself who is the residual claimant and, accordingly, suffers from repayment contracts providing inefficient incentives.

This paper contributes to the empirical literature on credit markets since, to the best of our knowledge, this is the first study comparing the properties of non-monotonic and standard debt contracts. We also complement the experimental literature on credit markets where there are only very few studies available to date; e.g., Brown and Zehnder (forthcoming) investigate the effect of information dissemination of loan defaults on

\footnotetext{
${ }^{*}$ Financial support from Maastricht University through METEOR is gratefully acknowledged.
} 
repayment behavior and Fehr and Zehnder (2006) study the role of reputation in credit markets.

A related strand of experimental literature on principal-agent relationships firmly establishes that moral hazard affects agents' behavior. It is has been shown that agents' behavior responds to the design of employment contracts and the context of the agency relationship. E.g., DeJong, Forsythe and Lundholm (1985) demonstrate the relevance of moral hazard with flat wage employment contracts. Fehr, Kirchsteiger, and Riedl (1993) and Irlenbusch and Sliwka (2005) show that agents' effort increases in the generosity of flat wages. Fehr, Klein, and Schmidt (2007), on the other hand, report that bonus contracts outperform flat wage contracts, and Gneezy and Rustichini (2000) find that agents' output is higher than under flat wages only when piece rates are substantial. Anderhub, Gächter, and Königstein (2002) show that agents' respond to incentives provided by linear wage contracts. Falk and Kosfeld (2007) study detrimental effects of minimum performance requirements. Brandts and Charness (2004) and Owens and Kagel (2006) investigate the impact of competitive imbalances and minimum wages. The evidence provided by these studies demonstrates that, while incentives matter, contracts' success seems to crucially depend on the details of contract design: subtle changes can have large behavioral effects, as exemplified by the U-shaped impact of piece-rate size. Therefore, it is a priori not clear how non-monotonic contracts perform as compared to standard debt contracts.

The paper is organized as follows. Section 2 describes the theoretical model, section 3 summarizes the experimental design, section 4 reports our experimental results, and section 5 concludes.

\section{A simple model of entrepreneurial external financing}

This section introduces a simple model of entrepreneurial external financing that serves as foundation for our experimental investigation. It is a discrete variant of Innes (1990).

Consider an entrepreneurial project with random return $Z$. The underlying probability function is such that greater entrepreneurial effort increases the likelihood of outcomes with high returns. There are $n$ states. The project return in state $i$ is denoted by $z_{i} \geq 0$. Return states are numbered in ascending order, i.e. $z_{i}<z_{j}$ if $i<j$. The probability of state $i$ depends on entrepreneurial effort $x \in[0, \bar{x}]$ and is given by $p_{i}(x) \geq 0$ where $p_{i}(x)$ is twice-differentiable. For a proper probability distribution assume $\sum_{i} p_{i}(x)=1$ and $\sum_{i} p_{i}^{\prime}(x)=0$. To model that greater effort increases the probability for higher return states to occur, suppose that the monotone likelihood ratio property is satisfied, ie. for all $z_{i}<z_{j}$ we have $p_{i}^{\prime}(x) / p_{i}(x)<p_{j}^{\prime}(x) / p_{j}(x)$ implying $\partial E[Z \mid x] / \partial x>0$, cf. Milgrom (1981). To ensure an interior solution, suppose marginal benefit of effort does not grow to infinity, i.e. $\lim _{x \rightarrow \bar{x}} \partial E[Z \mid x] / \partial x$ is finite.

The project requires start-up cost $\Gamma>z_{1} \cdot{ }^{1}$ The entrepreneur is endowed with wealth $W$. The amount of external finance required to start the project is $D \equiv \Gamma-W$.

\footnotetext{
${ }^{1}$ If the start-up cost is not larger than the lowest project return $z_{1}$, the financing problem is trivial.
} 
Since we inquire into the effects of external financing schemes on entrepreneurial activity, $D>0$. For simplicity, let $W=0$. We assume the entrepreneur is subject to limited liability such that the realized project return constrains repayment in low return states. A feasible repayment contract $\vec{t}$ is characterized by $\vec{t}=\left(t_{1}, t_{2}, \ldots, t_{n}\right)$ such that $t_{i} \leq z_{i}$ due to limited liability, where $t_{i}$ denotes the contracted amount of repayment in state $i$.

The preferences of the entrepreneur are additively separable in income $y$ and effort $\operatorname{cost} c(x)$

$$
u(x, y)=y-c(x)
$$

where $c(0)=0, c^{\prime}(x)>0, c^{\prime \prime}(x)>0$ and $\lim _{x \rightarrow \bar{x}} c^{\prime}(x)=\infty$. Since the entrepreneur's income in state $i$ is the difference of realized project return and contracted repayment, the entrepreneur's maximization problem for any given contract $\vec{t}$ is given by:

$$
\max _{x} E U(x, \vec{t})=\sum_{i=1}^{n} p_{i}(x)\left(z_{i}-t_{i}\right)-c(x) .
$$

Expected utility is maximized by effort level $\widetilde{x}(\vec{t})$. For ease of exposition, let $c(x)$ be sufficiently concave to always guarantee strict concavity of the objective function. Then, the first order condition of the maximization problem characterizes a unique global maximum of entrepreneurial expected utility: ${ }^{2}$

$$
\sum_{i=1}^{n} p_{i}^{\prime}(\widetilde{x}) z_{i}=c^{\prime}(\widetilde{x})+\sum_{i=1}^{n} p_{i}^{\prime}(\widetilde{x}) t_{i}
$$

The LHS of (1) gives marginal (expected) project return of additional effort. The first term of the RHS is marginal effort cost and the second term is marginal (expected) repayment to the lender. If marginal repayment does not vanish from (1), the repayment contract distorts the entrepreneur's effort choice leading to inefficient effort as compared to the first-best level $x^{*}$ that prevails in the absence of external financing, i.e. $t_{i}=0 \forall i$.

Standard debt contracts essentially reduce the repayment structure to a flat repayment claim $\tau$ independent of the realized return state. Due to binding limited liability, the actual repayment to the lender is smaller than $\tau$ whenever the realized project return falls short off the flat repayment claim. Using our contract notation, a standard debt contract $\vec{t}$ sdc is characterized by

$$
t_{i}^{\text {sdc }}= \begin{cases}\tau & \text { if } z_{i} \geq \tau \\ z_{i} & \text { otherwise }\end{cases}
$$

Under a standard debt contract, the entrepreneur shares with the lender the benefit of increased expected project return created by additional effort while bearing total marginal

\footnotetext{
${ }^{2}$ Due to the generality of feasible contracts and revenue distributions, it is possible to find contracts that imply a strictly negative marginal entrepreneurial income net of repayment even with zero effort (e.g., a contract that always requires full repayment except for the lowest state where no repayment is required.) Then, it is impossible to satisfy the first-order condition (1) and a boundary solution emerges such that $\widetilde{x}(\vec{t})=0$.
} 
effort cost. As can be easily seen, the marginal repayment term in (1) does not vanish under such a contract, so that the standard debt contract suffers from inherent inefficiency (Proposition 1a). However, it is possible to design Pareto-improving contracts. These contracts are characterized by a non-monotonic repayment structure in the sense that repayment in some higher-return states is lower than repayment in some lower-return states. By decreasing repayment in high-return states, marginal repayment to the lender - being strictly positive under standard debt contracts - is reduced while the expected repayment to the lender can be preserved. It follows that the deviation from first-best effort and the implied welfare loss with non-monotonic contracts are smaller than under standard debt contracts due to better incentives provided by the former. If designed accordingly, non-monotonic contracts can even lead the entrepreneur to exert first-best effort and eliminate any welfare loss (Proposition 1b).

Proposition 1. (Non-monotonic contracts outperform standard debt contracts)

(a) Standard debt contracts lead to inefficiently low effort, thus giving rise to welfare losses.

(b) There exist non-monotonic contracts that are superior to standard debt contracts in terms of entrepreneurial profit and welfare. Non-monotonic contracts can implement firstbest effort.

Proof. See appendix A.

A numerical example that illustrates the potential magnitude of welfare gains through non-monotonic contracts and that we experimentally investigate is provided in section 3 .

\section{Experimental design}

\subsection{Model parameterization, treatments and theoretical predic- tions}

In the experiment, we implement the model introduced in section 2 with three states and linear probability functions. Project revenues and probability functions for states 1, 2, and 3 to occur are as follows:

$$
\begin{array}{ll}
z_{1}=500 \mathrm{ECU} & \text { with } p_{1}(x)=0.6-0.6 \frac{x}{100} \\
z_{2}=9,000 \mathrm{ECU} & \text { with } p_{2}(x)=0.4 \\
z_{3}=10,000 \mathrm{ECU} & \text { with } p_{3}(x)=0.6 \frac{x}{100}
\end{array}
$$

where effort $x \in[0,100]$. By increasing effort, probability is shifted from the low project return of $500 \mathrm{ECU}$ to the high project return of 10,000 ECU. This can be thought of as probability mass being shifted from the low to the intermediate return to the same extent as from the intermediate to the high return. 
The entrepreneur faces effort cost $c(x)=0.5 x^{2}$. The start-up investment of the project is fixed at $\Gamma=3,120 \mathrm{ECU}$. The rate of return an outside lender requires to finance the project is $r=0.25$.

We investigate three treatments that differ in the specification of the repayment contract only. As a benchmark we run a self-financing treatment (NoRepay), in which there is no repayment at all. Furthermore, we study the standard debt contract condition (SDC) and the non-monotonic contract condition (NMC), in which subjects are exposed to the respective kind of repayment contract. The required expected repayment to the lender, $(1+r) \Gamma$, determines the state-contingent repayments under both contracts. Importantly, both contracts lead to the same expected repayment of 3,900 ECU. Table 1 summarizes all repayment contracts.

\begin{tabular}{crrr}
\hline Repayment & \multicolumn{1}{c}{ SDC } & \multicolumn{1}{c}{ NMC } & NoRepay \\
\hline$t_{1}$ & $500.00 \mathrm{ECU}$ & $500.00 \mathrm{ECU}$ & $0 \mathrm{ECU}$ \\
$t_{2}$ & $7,383.30 \mathrm{ECU}$ & $9,000.00 \mathrm{ECU}$ & $0 \mathrm{ECU}$ \\
$t_{3}$ & $7,383.30 \mathrm{ECU}$ & $500.00 \mathrm{ECU}$ & $0 \mathrm{ECU}$ \\
\hline
\end{tabular}

Table 1: Repayment contracts by treatment

Table 2 summarizes the theoretical predictions. Evidently, the restriction to standard debt contracts leads to a loss in total surplus. Additionally, the entrepreneur's payoff is substantially smaller. If the standard debt contract is replaced by a repayment-equivalent non-monotonic contract, total surplus increases by $55 \%$, while the surplus accruing to the entrepreneur more than doubles. ${ }^{3}$

\begin{tabular}{lccc}
\hline & SDC & NMC & NoRepay \\
\hline effort & 15.7 & 57.0 & 57.0 \\
total surplus & $1,551.66 \mathrm{ECU}$ & $2,404.50 \mathrm{ECU}$ & $2,404.50 \mathrm{ECU}$ \\
entrepreneur's EU & $769.93 \mathrm{ECU}$ & $1,624.50 \mathrm{ECU}$ & $2,404.50 \mathrm{ECU}$ \\
\hline
\end{tabular}

Table 2: Theoretical predictions for effort, total surplus, and expected payoff

Behavior in the laboratory that deviates from our theory-based predictions which assume risk-neutrality may be attributable to the effects of individual risk preferences such as various degrees of risk-aversion. To address this concern, we reduce the risk in subjects' payoffs by paying them the average payoff over 50 different projects, with outcomes determined by independent draws from the probability distribution determined by effort choice instead of using the payoff realized for a single project. This method was successfully introduced by Kirchkamp, Reiss, and Sadrieh (2006) in an auction setting.

\subsection{Procedures and other details}

The experiment was programmed using z-tree (Fischbacher, 2007) and run at the Erfurt Laboratory for Experimental Economics (eLab). Subjects were recruited for each session

\footnotetext{
${ }^{3}$ The exact numbers are $54.96 \%$ and $110.99 \%$.
} 
using ORSEE (Greiner, 2004). No subject participated in more than one session. We ran one session for each treatment, obtaining twelve independent observations per treatment.

On the day, subjects were welcomed and randomly assigned to private cabins. Written instructions were handed to them before being read aloud by the experimenter. Subsequently, subjects entered their cubicles and had some time to go over the instructions again and ask any questions they might have. Questions were answered individually.

Subjects played 15 repetitions of the game and were paid according to their individual performance. The experimental sessions lasted for one hour or less, average earnings being $€ 9.65$ ( $\approx$ US\$ 12.50). Payments were settled individually to ensure subjects' anonymity.

\section{Experimental Results}

\subsection{Effects of contract types on effort choice}

Result 1. In the experiment, standard debt contracts lead to inefficiently low effort levels that decrease over time.

Figure 1 depicts average effort by treatment and by round. As the graph for treatment SDC suggests (left panel), standard debt contracts lead subjects to implement inefficiently low levels of effort as predicted by theory. In 10 of 15 rounds the sign test reveals highly significant differences between observed median effort and first-best effort $x^{*}=57$ ( $p<0.007$, two-tailed); for the remaining five rounds at the beginning of the experiment (rounds 1-4 and 8), observed differences are insignificant $(p>0.145){ }^{4}$

Result 2. The non-monotonic contract leads subjects to mirror the effort choice observed in the absence of repayment contracts.

In line with the theoretical prediction, the non-monotonic contract reproduces the effort choice observed under the no-repayment condition, as a comparison of the middle and right panels of figure 1 indicates. Roundwise comparison of effort choices under NMC to those under NoRepay reveals no significant differences in 14 out of 15 rounds (two-tailed Mann-Whitney $U$ test, $p>0.132$ ); there is one weakly significant difference in round 15 , $p=0.0882$.

Result 3. The non-monotonic contract induces more efficient effort levels than the standard debt contract.

The data depicted in the left panel and the middle panel of figure 1 clearly demonstrate that the standard debt contract implies substantially smaller effort choices than the nonmonotonic contract. Roundwise comparison of effort observed in treatment NMC to that observed in treatment SDC reveals highly significant differences in 10 of 15 rounds (two-tailed Mann-Whitney $U$ test, $p<0.007$ ). Three more comparisons show significant differences $(p<0.026)$, only differences in rounds 1 and 2 are insignificant.

\footnotetext{
${ }^{4}$ Using two-tailed parametric $t$-tests, we find significant differences in 13 of 15 rounds: In 10 rounds we observe highly significant differences $(p<0.0005$, rds. 5-7 and 9-15). In round 8, there is a significant difference with $p=0.0143$ and in rounds 3 and 4 we find $p<0.075$. For rounds 1 and $2, p>0.185$.
} 


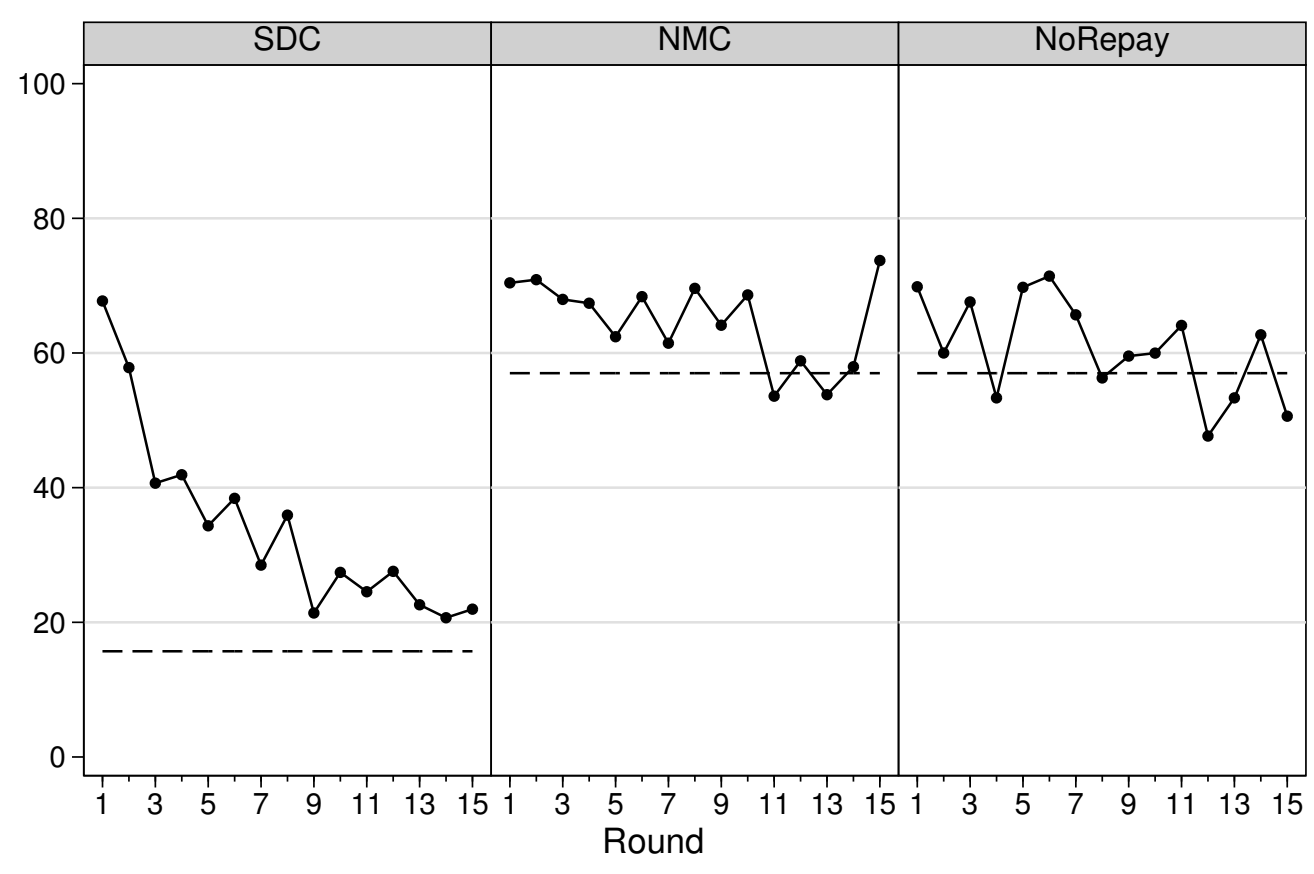

Average effort - ---- Predicted effort

Note: The figure depicts average effort (solid lines) over rounds under the standard debt contract (left), the non-monotonic contract (middle), and if there is no repayment (right). The theoretical effort prediction is indicated by dashed lines.

Figure 1: Average effort and predicted effort by round

\subsection{Effects of contract types on entrepreneurial income and on total surplus}

Result 4. Observed entrepreneurial income (net of effort cost and repayment) is on average $170 \%$ greater under the non-monotonic contract than under the standard debt contract.

Figure 2 highlights that the income of entrepreneurs in the NMC treatment is much greater than in the SDC treatment. Using data for rounds 11-15 only, we find that NMC income exceeds SDC income by $170 \%$. If earlier rounds are included, non-monotonic contracts perform even better, e.g. NMC income tops SDC income by $360 \%$ on average if data for rounds $3-15$ is used. ${ }^{5}$

Using the two-tailed non-parametric Mann-Whitney $U$ test for a roundwise comparison of entrepreneurial income (net of agency costs and repayment), we find that the difference in median income is highly significant in 12 of 15 rounds $(p<0.007)$. In two more rounds, income differences are significant $(p<0.05)$ and in another weakly significant $(p=0.0647)$.

Result 5. Standard debt contracts lead to a substantial welfare loss that can be eliminated completely if, instead, repayment-equivalent non-monotonic contracts are used.

\footnotetext{
${ }^{5}$ Percentages were calculated by taking the average income over subjects and the respective rounds.
} 


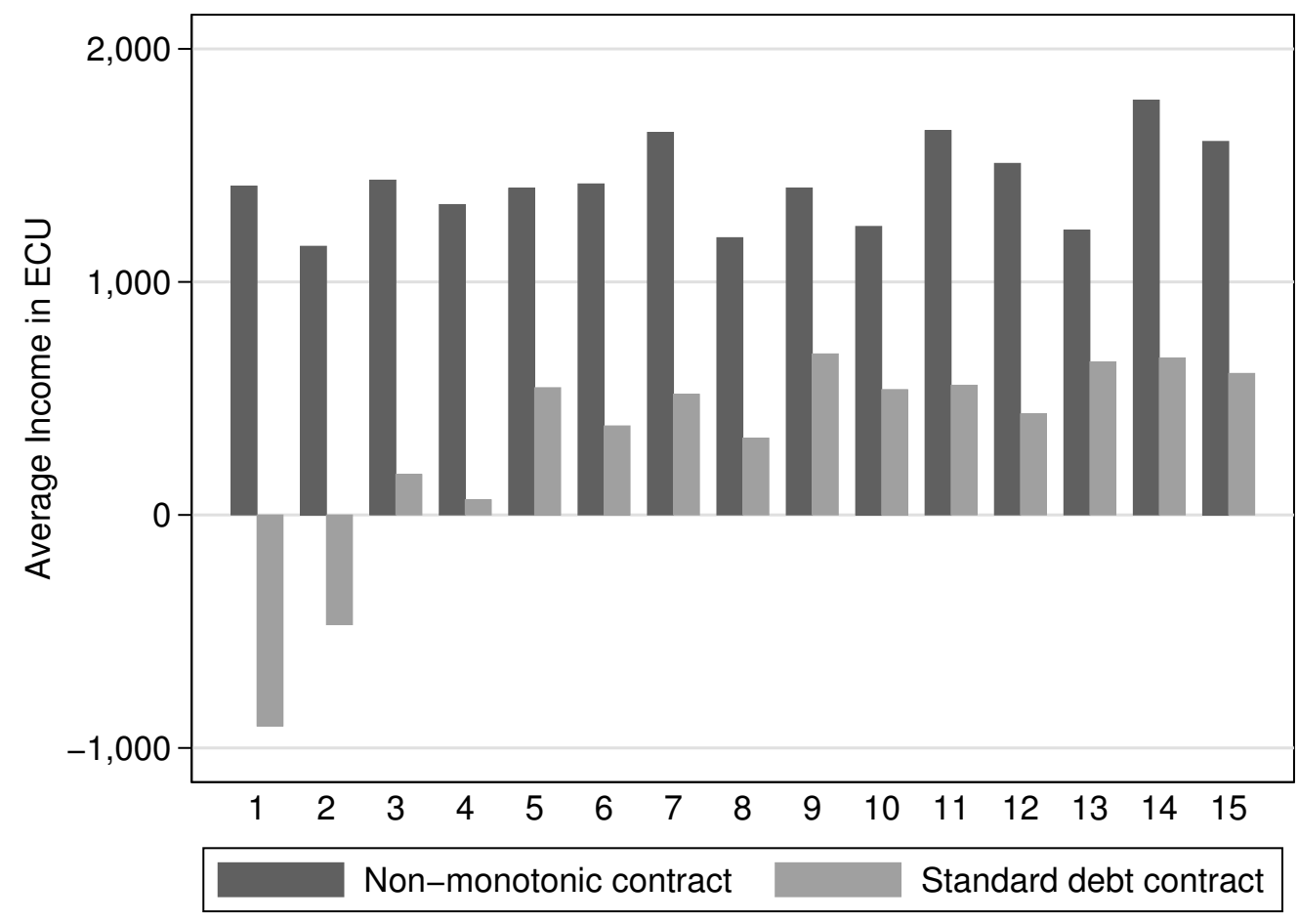

Figure 2: Average round income of entrepreneurs under NMC and SDC

Using a bar diagram, Figure 3 illustrates how much additional total surplus would have been created in the SDC treatment if, instead of the standard debt contract, a nonmonotonic contract had been used. The figure reveals that in the first four rounds of the experiment, there is essentially no welfare disadvantage of the standard debt contract. ${ }^{6}$ Clearly, these initial effort levels are suboptimal and yield negative round incomes, as is obvious from inspecting figure 2. In the course of the experiment, subjects in the SDC treatment apparently become aware of that smaller effort leads to larger round incomes and reduce their effort choices accordingly. As effort levels in the SDC treatment decrease, the observed welfare disadvantage of standard debt contracts sharply grows. In the last part of the experiment (rounds 11-15), effort levels appear stable. On average, the use of the non-monotonic contract would have increased welfare in the SDC treatment by approximately $30 \%$ in these five rounds.

Restricting attention to data from the last part of the experiment (rounds 11-15) where effort choices under SDC appear to have converged (see figure 3), we find that observed welfare in the NMC treatment is significantly greater than in the SDC treatment in all of these five rounds (Mann-Whitney $U$ test, $p<0.057$, two-tailed).

\footnotetext{
${ }^{6}$ In the first two rounds, SDC welfare is even slightly higher than NMC welfare. This is due to the fact that quite large effort levels are initially chosen in the SDC treatment, similar to those effort levels observed in the NMC treatment, but somewhat closer to first-best effort which is indicated by the horizontal line in the Figure.
} 

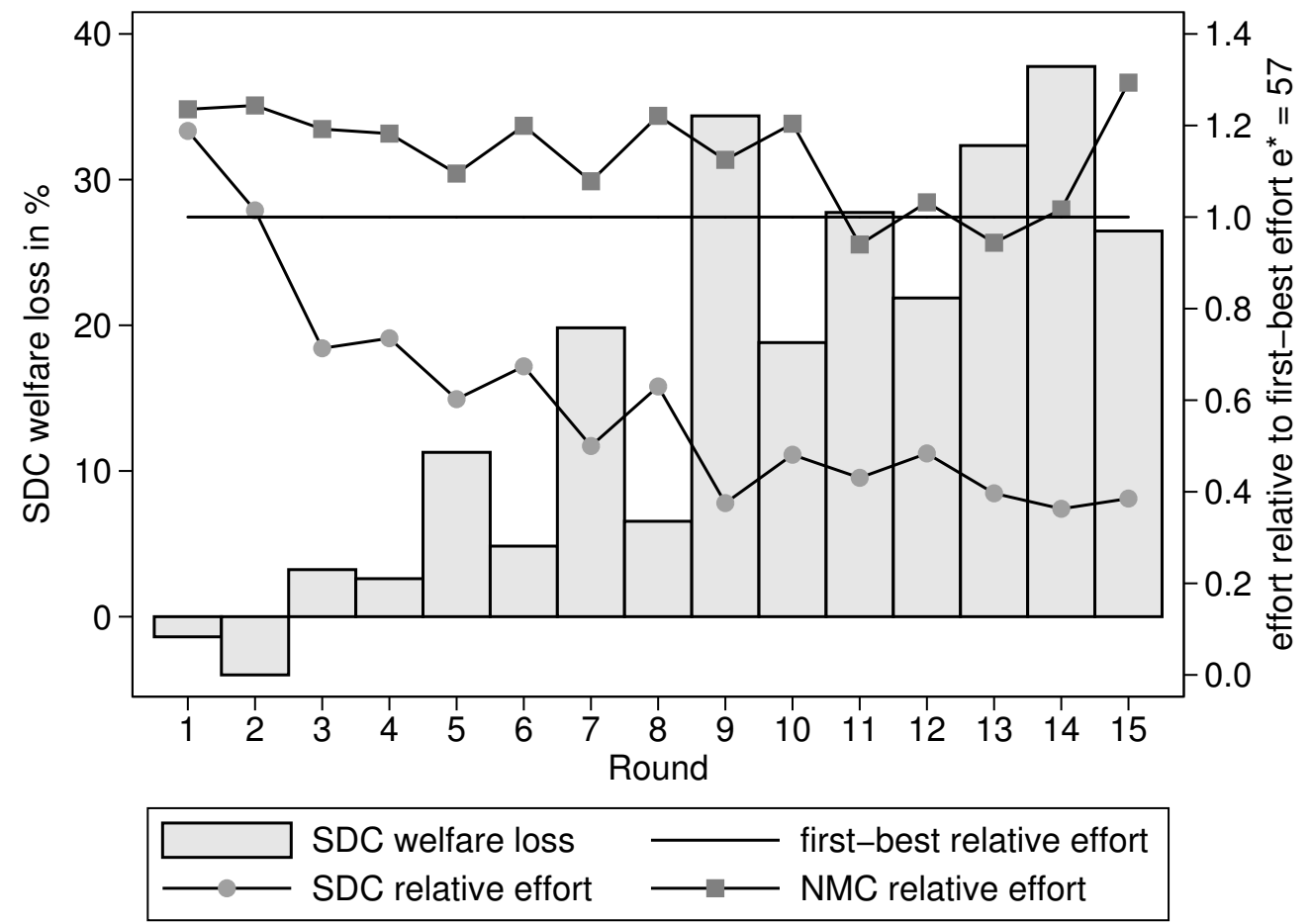

Note: The figure depicts the additional total surplus (in \%) that is created on average if the SDC is replaced by the corresponding NMC, given average effort levels observed under both contract conditions. This measure of welfare loss is shown as a series of bars (left scale). Furthermore, the figure illustrates average effort observed in both contract conditions relative to first-best effort (right scale). Eg., in round 5, NMC average effort exceeds first-best effort by roughly $10 \%$ while SDC average effort falls short off it by $40 \%$. Finally, the first-best effort benchmark (where total surplus is maximized) is represented by a horizontal line at unity (right scale).

Figure 3: Welfare loss with a standard debt contract, but eliminable by a non-monotonic contract

\section{Concluding remarks}

From a theoretical perspective, in our setting of entrepreneurial external finance, standard debt contracts provide inferior incentives to the entrepreneur. Accordingly, welfare losses and reduced entrepreneurial profit emerge due to inefficiently low effort choice. Nonmonotonic repayment contracts have been shown to overcome these negative properties of the standard debt contract.

We have put these theory-based predictions to the experimental test. Our results confirm the superiority of non-monotonic repayment contracts. Importantly, this study is only a first, albeit successful, step towards a better understanding of the potential and the properties of non-monotonic contracts. E.g., it is important to investigate the downsides of non-monotonic contracts, first and foremost higher informational requirements and susceptibility to sabotage. 


\section{References}

Brandt, Jordi and Gary Charness (2004): Do Labour Market Conditions Affect Gift Exchange? Some Experimental Evidence. Economic Journal 114, 684-708.

Brown, Martin and Christian Zehnder (forthcoming): Credit Registries, Relationship Banking and Loan Repayment. Journal of Money, Credit, and Banking.

DeJong, Douglas V., Forsythe, Robert, and Russell J. Lundholm (1985): Ripoffs, Lemons, and Reputation Formation in Agency Relationships: A Laboratory Market Study. Journal of Finance 40(3), 809-820.

Falk, Armin and Michael Kosfeld (2006): The Hidden Costs of Control. American Economic Review 96, 1611-1630.

Fehr, Ernst, Kirchsteiger, Georg, and Arno Riedl (1993): Does Fairness prevent Market Clearing? An Experimental Investigation. Quarterly Journal of Economics 108(2), 437460.

Fehr, Ernst, Klein, Alexander, and Klaus M. Schmidt (2007): Fairness and Contract Design. Econometrica 75(1), 121-154.

Fehr, Ernst and Christian Zehnder (2006): Reputation and Credit Market Formation, NCCR Finrisk Working Paper No. 179.

Gneezy, Uri and Aldo Rustichini (2000): Pay Enough or Don't Pay at All. Quarterly Journal of Economics 115(3), 791-810.

Innes, R.T. (1990): Limited liability and incentive contracting with ex ante action choices. Journal of Economic Theory 52, 45-67.

Irlenbusch, Bernd and Dirk Sliwka (2005): Transparency and reciprocal behavior in employment relations. Journal of Economic Behavior and Organization 56(3), 383-403.

Kirchkamp, Oliver, Reiss, J. Philipp, and Karim Sadrieh (2006): A pure variation of risk in first-price auctions. METEOR Research Memorandum 06/058.

Milgrom, Paul R. (1981): Good news and bad news: Representation theorems and applications. Bell Journal of Economics 13, 369-378.

Owens, Mark F. and John Kagel (2006): Minimum Wage Restrictions and Employee Effort in Labor Markets with Gift Exchange Present. Working Paper, Ohio State University. 


\section{Appendix}

\section{A Proof of Proposition 1}

Proof.

(a) Firstly, we show that a repayment contract that implies a strictly positive marginal repayment leads the entrepreneur to choose an effort level smaller than first-best effort, $x^{*}$. Secondly, we show that marginal repayment is strictly positive under any standard debt contract.

Let $\widetilde{x}$ be the solution of the entrepreneur's maximization problem. Denoting the marginal repayment to the lender by $M R(x)$, the first-order condition (1) can be rewritten as:

$$
\sum_{i=1}^{n} p_{i}^{\prime}(\widetilde{x}) z_{i}-c^{\prime}(\widetilde{x})-M R(\widetilde{x})=0
$$

by the implicit function theorem,

$$
\frac{d \widetilde{x}}{d M R}=\frac{1}{\sum_{i=1}^{n} p_{i}^{\prime \prime}(\widetilde{x}) z_{i}-c^{\prime \prime}(\widetilde{x})-M R^{\prime}(\widetilde{x})}<0
$$

where the denominator is the maximization problem's second-order condition so that a strictly positive marginal repayment implies $\widetilde{x}<x^{*}$.

Expected repayment to the lender under any standard debt contract is given by $\sum_{i=1}^{m-1} p_{i}(x) z_{i}+\sum_{i=m}^{n} p_{i}(x) \tau$ where $m$ denotes the index of the smallest payoff state that allows to fully repay the fixed payment of the standard debt contract $\tau$, i.e. $z_{m}=$ $\min \left\{z_{i}: z_{i} \geq \tau\right\}$. Rewrite expected repayment under the standard debt contract and differentiate with respect to effort to obtain marginal repayment as

$$
M R^{\mathrm{sdc}}(x)=z_{i} \sum_{i=1}^{n} p_{i}^{\prime}+\left(z_{2}-z_{1}\right) \sum_{i=2}^{n} p_{i}^{\prime}+\ldots+\left(z_{m-1}-z_{m-2}\right) \sum_{i=m-1}^{n} p_{i}^{\prime}+\left(\tau-z_{m-1}\right) \sum_{i=m}^{n} p_{i}^{\prime} .
$$

By definition of a proper distribution function, the sum of marginal probabilities equals zero, $\sum_{i=1}^{n} p_{i}^{\prime}=0$. Thus, the first summation vanishes. All other summations differ from the first one in that marginal probabilities for low revenue states are not part of the summation. By the revenue distribution's MLRP property, it is the lowest payoff states that are assigned negative marginal probabilities, so that all remaining summations are strictly positive. It follows that marginal repayment under any standard debt contract is always strictly positive.

(b) Consider any standard debt contract $\vec{t}$ such that $t_{n-1}<z_{n-1}$. It follows feasibility of small changes of the contract structure such that $d t_{n-1}=-p_{n}(\widetilde{x}) / p_{n-1}(\widetilde{x}) d t_{n}>0$. The resulting contract structure is non-monotonic since under the SDC repayments in the two highest revenue states are the same while under the modified contract repayment in the highest revenue state is smaller than that in the second-highest. Examining the effect of 
the contract modification on optimal effort yields, by (1),

$$
\left.\frac{d \widetilde{x}}{d t_{n-1}}\right|_{d t_{n-1} / d t_{n}=-p_{n} / p_{n-1}}=\frac{p_{n-1}(\widetilde{x})}{\mathrm{SOC}} \cdot\left[\frac{p_{n-1}^{\prime}(\widetilde{x})}{p_{n-1}(\widetilde{x})}-\frac{p_{n}^{\prime}(\widetilde{x})}{p_{n}(\widetilde{x})}\right]>0,
$$

where the first factor is negative by strictly positive probability in state $n$ and second order condition SOC $\equiv \sum_{i=1}^{n} p_{i}^{\prime \prime}(\widetilde{x}) z_{i}-c^{\prime \prime}(\widetilde{x})-\sum_{i=1}^{n} p_{i}^{\prime \prime}(\widetilde{x}) t_{i}<0$, and the second factor is negative by MLRP. Therefore, the modified repayment structure induces the entrepreneur to exert more effort than exerting under the considered SDC.

The increase of effort implies greater total surplus due to the fact that total surplus is strictly increasing in effort on $\left[0, x^{*}\right]$ and effort under any SDC satisfies $\widetilde{x}<x^{*}$. Since marginal repayment under any SDC is strictly positive (see part (a) of this proof), the expected repayment, denoted by $R(\widetilde{x}(\vec{t}))$, is greater than that under the modified repayment contract:

$$
\left.\frac{d R(\widetilde{x}(\vec{t}))}{d t_{n-1}}\right|_{d t_{n-1} / d t_{n}=-p_{n} / p_{n-1}}=\left.\left[\sum_{i=1}^{n} p_{i}^{\prime}(\widetilde{x}) t_{i}\right] \cdot \frac{d \widetilde{x}}{d t_{n-1}}\right|_{d t_{n-1} / d t_{n}=-p_{n} / p_{n-1}}>0 .
$$

Evidently, expected repayment can be reduced to the level prevailing under the considered SDC by decreasing repayment in every state by the same amount so that optimal effort and total surplus do not change. Therefore, there exist non-monotonic contracts that are superior to the considered SDC in terms of total surplus and entrepreneurial profit.

\section{B Instructions (Translation from German)}

[Part I:] General explanations for participants

You are now participating in an economic experiment that is financed by METEOR. If you carefully read the following explanations, you can earn a substantial amount of money, contingent on your decisions. Therefore, it is very important that you read these explanations carefully.

The instructions handed out to you are for your private information only.During the experiment there is a strict prohibition of any kind of communication. If you do not abide by this rule, you will be excluded from the experiment as well as any payments. If you have any question, please, raise your arm. We will then answer your question COMING TO YOUR CUBICLE.

During the experiment we will not count in Euros but in ECU (Experimental Currency Units). Therefore, your total earnings will first be calculated in ECU. The total amount of ECU you attain during the experiment will be converted to Euros at the end of the experiment and paid in cash.

\section{[Part II:] Information regarding the experiment}

The experiment today is divided into separate rounds. In total, there will be 15 rounds. 
The following elaborations explain the course of action of the experiment for each round.

Each round, you undertake a new project and decide on how much effort you want to invest into the project. By choosing your effort level, you determine the probabilities of the project to attain a low, intermediate, or high revenue. At the same time, a higher effort choice leads to higher costs. Undertaking the project requires start-up costs of EUR 3120. [The next two sentences were only included in the instructions for SDC-P50 and NMC-P50: As you do not dispose of the start-up capital needed for the start-up investment, you have to raise the capital on the capital market. You are acting under limited liability: in case your project revenue does not cover the fixed repayment to the capital provider, only your project revenue will be used for repayment, the remainder will be waived.] [The next two sentences were only included in the instructions for BASP50: Undertaking the project requires start-up costs of EUR 3120 . You dispose of the necessary start-up capital and you do not have to raise the capital on the capital market.]

Course of action At the beginning of each round, you are asked to set the effort level $X$ for this round's project. The effort level cannot be negative or exceed 100, and may only exhibit one decimal place.

The costs arising from your effort are $\frac{1}{2} X^{2}$. The project revenue is random and may take on a low, intermediate, or high level. By choosing your effort level $X$, you can influence the probabilities for a low or a high project revenue. The higher your effort level, the lower the probability of a low revenue and the higher the probability of a high revenue. In particular:

- probability of the low

revenue of $\quad 500 \mathrm{ECU}: \quad 60 \%-\frac{X}{100} \cdot 60 \%$

- probability of the intermediate revenue of 9.000 ECU: $40 \%$

- probability of the high revenue of 10.000 ECU: $\frac{X}{100} \cdot 60 \%$

To ease calculating probabilities and effort costs, on the input screen (see figure 1 [Please see the first screenshot in the next section]) you may enter any number of values into the effort entry field and have the according probabilities and effort costs displayed by clicking on the button "calculate probabilities". By clicking on the button "confirm choice", you make your decision in this round irrevocable.

[The following paragraph was only included in the instructions for SDC-P50:

Fixed repayment to the capital provider Out of the project revenue, the capital provider receives ECU 7383.30 as fixed repayment for financing the project. In case the project revenue does not cover the fixed repayment to the capital provider, you will only repay the project revenue, the remainder will be waived.]

[The following paragraph was only included in the instructions for NMC-P50:

Fixed repayment to the capital provider Out of the project revenue, the capital provider receives ECU 500 in case of a low revenue, ECU 9000 in case of an intermediate revenue, and ECU 500 in case of a high revenue as a fixed repayment for financing the project.] 
[The following paragraph was only included in the instructions for SDC-P50:

Your project income Your project income equals the project revenue minus repayment costs and minus effort costs, i.e.:

- in case of a low revenue:

$$
\begin{array}{rrr}
500-500-\frac{1}{2} X^{2} & = & -\frac{1}{2} X^{2} \mathrm{ECU} . \\
9.000-7.383,30-\frac{1}{2} X^{2} & = & 1.616,70-\frac{1}{2} X^{2} \mathrm{ECU} . \\
10.000-7.383,30-\frac{1}{2} X^{2} & = & \left.2.616,70-\frac{1}{2} X^{2} \mathrm{ECU} .\right]
\end{array}
$$

- in case of an intermediate revenue:

- in case of a high revenue:

[The following paragraph was only included in the instructions for NMC-P50:

Your project income Your project income equals the project revenue minus repayment costs and minus effort costs, i.e.:

- in case of a low revenue:

$$
\begin{array}{rlr}
500-500-\frac{1}{2} X^{2} & = & -\frac{1}{2} X^{2} \text { ECU } \\
9.000-9.000-\frac{1}{2} X^{2} & = & -\frac{1}{2} X^{2} \text { ECU } \\
10.000-500-\frac{1}{2} X^{2} & = & 9.500-\frac{1}{2} X^{2} \text { ECU. }
\end{array}
$$

- in case of an intermediate revenue:

- in case of a high revenue:

[The following paragraph was only included in the instructions for BAS-P50:

Your project income Your project income equals the project revenue minus effort costs, i.e.:
- in case of a low
revenue:
$500-\frac{1}{2} X^{2} \mathrm{ECU}$
- in case of an intermediate
revenue:
$9.000-\frac{1}{2} X^{2} \mathrm{ECU}$.
- in case of a high
revenue: $\quad 10.000-\frac{1}{2} X^{2}$ ECU.]

Number of projects and round income In each round, you will undertake 50 identical projects. That is to say, by choosing your effort level you do not determine the revenue probabilities and effort costs of a single project only, but those of 50 independent projects. To this effect, each project's revenue will be determined by a random draw under the probabilities determined by your effort choice. All random draws are independent of each other. You will be shown the number of projects with low, intermediate, and high revenue as well as the project incomes on an informational screen (see figure 2 [Please see the second screenshot in the following section]). Your round income will be determined as follows:

\section{Your round income $=$ average revenue of the 50 projects.}

Payment At the end of the experiment you will be paid [in SDC-P50 and NMC-P50: EUR 0.0004] [in BAS-P50: EUR 0.00005] for each ECU on your ECU account. At the beginning of the experiment, an initial endowment of [in $S D C-P 50$ and $N M C-P 50$ : ECU 12500] [in BAS-P50: ECU 100 000] will be credited to your account to cover potential losses. Each round, your round income will be added to your account, so that your account balance either increases (in case of a positive round income) or decreases (in case of a negative round income). You can avoid losses with certainty by making decisions accordingly. In case your account balance falls below [in SDC-P50 and NMC-P50: ECU 2500] [in BAS-P50: ECU 20000], you may not continue the experiment.

If you have any questions, please, let us know by raising your hand. 


\section{Screenshots}

Figure 4 shows an input screen with hypothetical data for the SDC treatment. In the screenshot used in the set of instructions given to subjects, there was no data available.

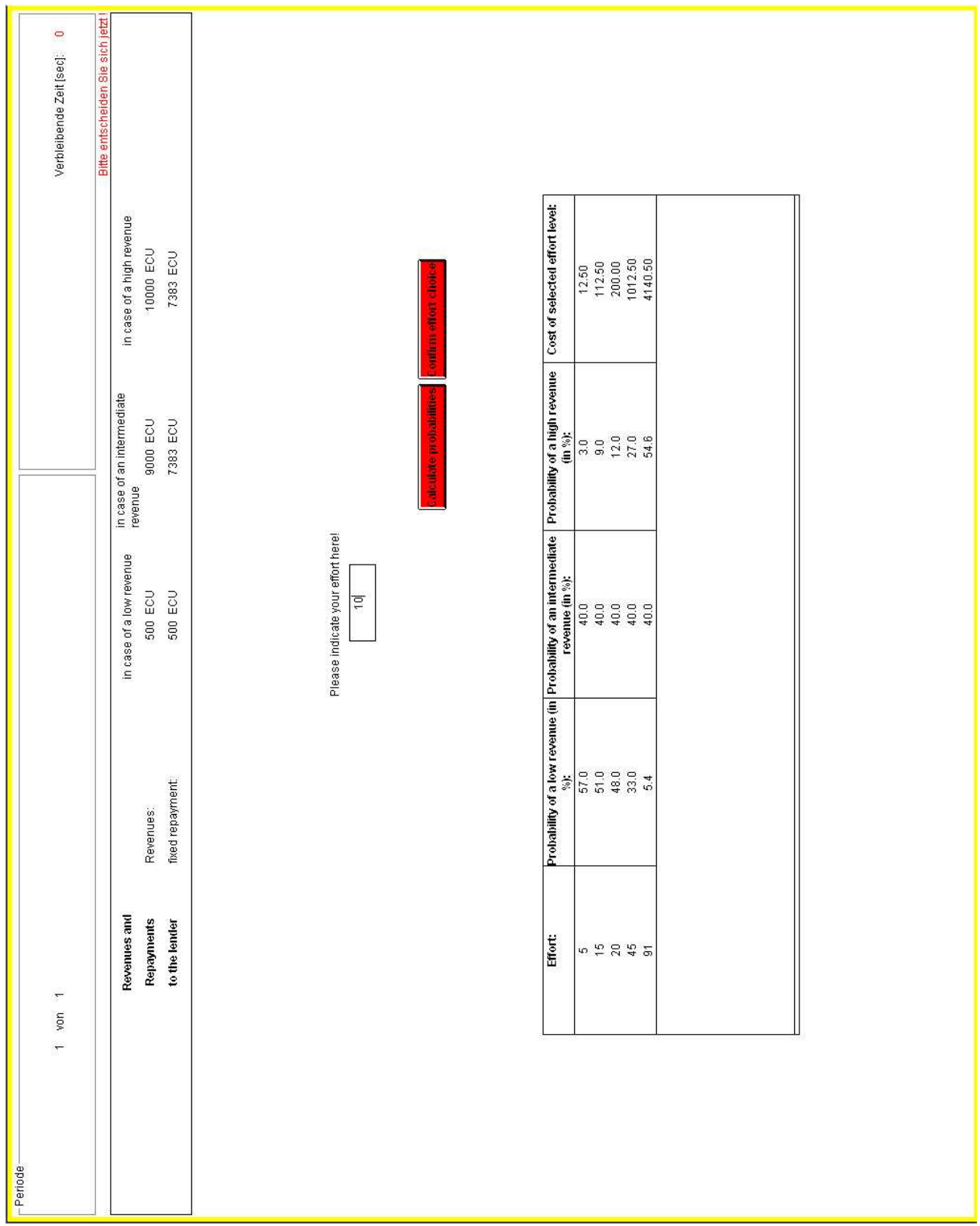

Figure 4: Input screen in the SDC treatment with hypothetical data (translation) 
Figure 5 shows the feedback screen with information about project outcomes and round income. A similar screenshot, also with data substituted by letters "XXX", was used in the set of instructions give to subjects.

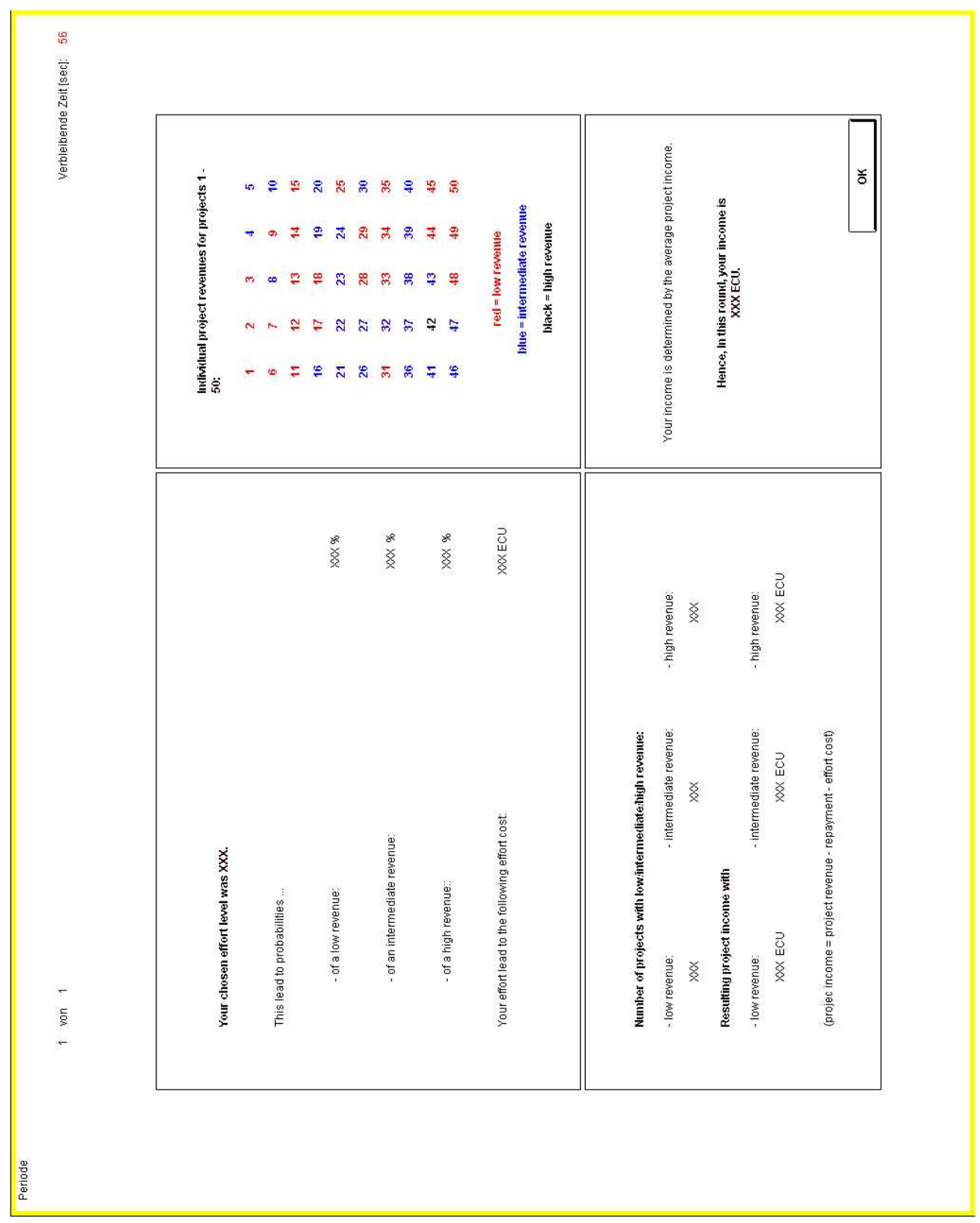

Figure 5: Feedback screen from instructions in SDC treatment with erased data (transl.) 